\title{
Surface-Level Actual Similarity Vs. Deep-Level Perceived Similarity: Predicting Leader-Member Exchange Agreement
}

\author{
K. Michele Kacmar \\ The University of Alabama \\ Kenneth J. Harris \\ Indiana University Southeast \\ Dawn S. Carlson \\ Baylor University \\ Suzanne Zivnuska \\ California State University - Chico
}

\begin{abstract}
Drawing upon similarity-attraction theory (Byrne, 1971), we explore whether deep-level perceived similarity or surface-level actual similarity is more predictive of agreement between supervisors and subordinates about the quality of their relationship (LMX). To examine this question we analyze supervisor-subordinate agreement on four antecedents of LMX: one surface-level similarity variable (relational demography), and three deep-level similarity variables (common perspective, receptiveness, and liking). Responses from a matched set of 203 supervisor-subordinate dyads indicate that deeplevel similarity matters more than surface-level similarity since all three deep-level perceptual variables explain variance in LMX agreement above and beyond the variance explained by surface-level actual similarity.
\end{abstract}

\section{Introduction}

Leader-member exchange (LMX) theory considers the quality of the relationship that develops between a supervisor and a subordinate (Graen \& Uhl-Bien, 1995). Despite the obvious dyadic nature of the relationship, LMX relationships are not often operationalized as such, but instead are narrowly defined considering the perspective of a single party (Graen \& Uhl-Bien, 1995; Schriesheim, Castro, \& Cogliser, 1999). The quality of the social exchange component in a relationship suggests that considering the extent to which supervisors and subordinates agree about the quality of their relationship would provide a more complete picture of that relationship. Thus, we believe that LMX agreement is a valuable tool in understanding this dyadic relationship that has not received enough research attention (Cogliser, Schriesheim, Scandura, \& Gardner, in press; Scandura, 1999) despite calls for an increased focus on LMX agreement (e.g., Gerstner \& Day, 1997).

Similarity-attraction theory (Byrne, 1971) provides direction for studying LMX agreement. This theory suggests that people tend to report more positive interactions with people who are similar to them than with those who are dissimilar (Byrne, 1971). Similarity-attraction theory is consistent with LMX theory, which suggests that when individuals in a dyad are of one mind concerning key relationship variables, they tend to like one another and develop relationships that are of high quality (Bauer \& Green, 
1996; Liden, Wayne, \& Stillwell, 1993). However, research studies examining similarity of surface-level demographic factors or deep-level perceptions of values, attitudes, and beliefs have been inconclusive (e.g., Engle \& Lord, 1997; Schriesheim et al., 1999; Schriesheim, Castro, Zhou, \& Yammarino, 2001; Vecchio \& Brazil, 2007).

One reason for the lack of consistent empirical findings may be that most of the studies mentioned above have failed to incorporate both the subordinate and supervisor perspectives. Additionally, the impact of similarity may depend on the type of similarity being studied (Allison, Armstrong, \& Hayes, 2001; Huang \& lun, 2006; Tyran \& Gibson, 2008). Some research points to the more consistent and lasting effect that deep-level perceptual similarity (perceived similarity of attitudes, values, and beliefs) has when compared to surface-level actual similarity (actual similarity in demographic characteristics) (e.g., Bauer \& Green, 1996; Harrison, Price, \& Bell, 1998; Phillips, Northcraft, \& Neale, 2006; Turban, Dougherty, \& Lee, 2002). These findings are consistent with LMX research that suggests deep-level perceived similarity may be a stronger construct for predicting LMX agreement than is surface-level actual similarity (e.g., Liden et al., 1993). Therefore, it is our contention that when considering surfacelevel actual similarity and deep-level perceived similarity at the same time, that deeplevel perceived similarity will have a greater impact than surface-level actual similarity on LMX agreement. In other words, we will examine which matters most --- surfacelevel actual similarity or deep-level perceived similarity from both the supervisor and subordinate perspectives.

The current study builds on past research by investigating matched pairs of supervisors and subordinates and includes multiple dimensions of surface-level actual similarity (i.e., age, race, and sex) in a relational demography variable, as well as three forms of deep-level perceived similarity (common perspective, receptiveness, and liking) on LMX agreement levels in supervisor-subordinate dyads. The three forms of deep-level perceived similarity represent dimensions of relationship quality and reflect the major theories underlying the dyadic supervisor-subordinate relationship - role theory (Kahn, Wolfe, Quinn, Snoek, \& Rosenthal, 1964), social exchange theory (Blau, 1964; Cropanzano \& Mitchell, 2005), and similarity-attraction theory (Byrne, 1971). Finally, we determine if deep-level perceived similarity has a stronger impact on LMX agreement than does surface-level actual similarity. Our approach furthers LMX agreement research by offering a much needed step in developing an understanding of the complex issues involved in supervisor-subordinate LMX agreement.

\section{LMX Agreement}

The central idea behind LMX as originally put forth (Dansereau, Cashman, \& Graen, 1973 ) is that different types of relationships develop between leaders (supervisors) and their members (subordinates). Through role (Kahn et al., 1964), social exchange (Blau, 1964), and attraction theories (Byrne, 1971), LMX focuses on the processes through which supervisors and subordinates evolve in their roles through dyadic transactions. A main premise of LMX research is that the quality of the LMX relationship, which develops through dyadic transactions, predicts important organizational and individual 
outcomes (Gerstner \& Day, 1997; Graen \& Uhl-Bien, 1995; Liden, Sparrowe, \& Wayne, 1997; Wang, Law, Hackett, Wang, \& Chen, 2005).

Despite theoretical underpinnings which describe relationships as a series of dyadic exchanges combined with calls from empirical researchers to incorporate the dyadic perspective in LMX research (Scandura, 1999), virtually no research has been done on dyadic agreement about the LMX relationship. In fact, Schriesheim et al. (1999; 2001) reported that the vast majority (over $90 \%$ ) of the extant LMX research analyzed raw scores from either the supervisor or the subordinate, and few studies employed dyadic analyses (e.g., Gregurus \& Ford, 2006). Thus, there is a need to investigate LMX dyadically. A dyadic investigation of LMX implies that both supervisor and subordinate perspectives on the quality of their relationship should be accounted for. We argue that one way of accounting for both perspectives is to assess the quality of the LMX relationship by calculating the extent to which the supervisor and subordinate agree in their assessment of their relationship quality (LMX agreement). Specifically, we explore the difference in LMX ratings between leaders and their members.

We chose four variables, suggested by theory and previous research that represent different forms of similarity to examine as predictors of LMX agreement. The first variable is relational demography, a measure of surface-level actual similarity, which represents how closely supervisors and subordinates match in terms of demographic characteristics. The three other variables, common perspective, receptiveness, and liking, measure the extent to which the supervisor and subordinate perceive that they are similar in terms of these deep-level relationship variables.

\section{Similarity}

Similarity has been suggested to have an important impact on the quality of relationships between individuals (Harrison et al., 1998). Similarity-attraction theory (Byrne, 1971) suggests a strong, positive relationship between similarity and interpersonal attraction. A guiding principle of this theory is the similarity attraction paradigm (Byrne, 1971), which posits that individuals are usually attracted to those who are similar to them (e.g., Engle \& Lord, 1997). Further, the more similarity individuals perceive with a relationship partner, the more positive their feelings for that person. In terms of LMX, both surface-level actual similarity (measured in terms of demographic variables) (e.g., McClane, 1991; Pelled \& Xin, 2000; Vecchio \& Brazil, 2007; Wayne \& Liden, 1995) and deep-level perceived similarity (e.g., Bauer \& Green, 1996; Liden et al., 1993), have found some support in predicting the quality of LMX relationships between supervisors and subordinates. What is not clear is how surface- and deep-level similarity differ, and which has a greater effect on LMX agreement. Thus, this study addresses this issue by including both surface-level and deep-level perceived similarity as antecedents of LMX agreement.

\section{Surface-level Actual Similarity}

\section{$\underline{\text { Relational demography }}$}


Surface-level actual similarity, as measured by demographic characteristics (i.e., age, gender, class, education, race), has been used as a predictor of LMX quality with mixed results (e.g., Bauer \& Green, 1996; Green, Anderson, \& Shivers, 1996; Pelled \& Xin, 2000). One possible reason for the inconsistent findings is that although single, independent demographic characteristics do not consistently predict LMX quality, combinations of the demographics may (Bauer \& Green, 1996; Gerstner \& Day, 1997). That is, while simply being different ages may not alter LMX quality significantly, the combined effect created by coupling the age difference with race and gender differences may be strong enough to influence LMX quality.

Relational demography is a variable that takes into consideration the impact of multiple surface-level similarities of individuals in a dyad (Harrison et al., 1998; Tsui \& O'Reilly, 1989). Surface-level characteristics, such as gender, age, and race, are permanent, usually observable, and easily measured (Harrison et al., 1998; Jackson, Stone, \& Alverez, 1993). Surface-level actual similarity focuses on patterns of similarity to investigate the impact of how dyads who are similar or dissimilar on the surface, form differential relationship qualities. Individuals who are demographically similar are more likely to have shared similar experiences, similar backgrounds, been treated the same, and react to situations in similar ways (Chatman, Polzer, Barsade, \& Neale, 1998). Similarity attraction theory (Byrne, 1971) suggests that these common experiences will enhance the degree of perceived similarity between supervisors and subordinates further increasing their positive feelings for their partner. Thus, the more similar individuals are on the surface, the more likely they are to have similar LMX perceptions (i.e., LMX agreement). Therefore, we predict

$\mathrm{H} 1$ : Surface-level actual similarity is positively related to supervisor-subordinate LMX agreement.

\section{Deep-level Perceived Similarity}

\section{Common Perspective}

Although surface-level actual similarity may exhibit strong effects on certain organizational phenomena, researchers have suggested that deep-level perceived similarity may be a stronger predictor (e.g., Liden et al., 1993) because people's perceptions are their reality (Lewin, 1947). The first construct we used to evaluate deeplevel perceptions of similarity was the degree to which the supervisor (subordinate) believes s/he shares a common perspective with the subordinate (supervisor) with respect to job-related attitudes and beliefs. This construct is based on previous studies which included similarity in values, outlook, perspective, attitudes, and abilities as predictors of LMX (e.g., Allison et al., 2001; Engle \& Lord, 1997; Liden et al., 1993; Phillips \& Bedeian, 1994). Like surface-level actual similarity, the relationship between common perspective and supervisor-subordinate relationship quality finds its foundation in similarity-attraction theory, as the more a person thinks s/he shares deep-level perspectives with his/her partner, the more likely the pair is to agree about appropriate 
behaviors in the workplace (Harrison et al., 1998), and have higher levels of LMX agreement. Just as surface-level actual similarity accounts for characteristics of both the supervisor and the subordinate, we examine the extent to which deep-level perceived similarity concerning work attitudes and beliefs has an impact on agreement about relationship quality. Formally, we predict

H2: Deep-level perceived similarity within supervisor-subordinate dyads about jobrelated attitudes and beliefs is positively related to supervisor-subordinate LMX agreement.

\section{Receptiveness}

Social exchange theory (Blau, 1964; Cropanzano \& Mitchell, 2005) suggests the social exchange between two people entails obligations, and when one person does something for another person there is an expectation of future return (Gouldner, 1960). In the LMX relationship, supervisors give certain advantages or benefits to individuals with whom they have higher quality LMX relationships (Liden et al., 1997). In return for these advantages, supervisors expect subordinates to help them with work tasks that are beyond the scope of the formal job description (Graen \& Uhl-Bien, 1995). The greater the perceived value of the commodities exchanged, both tangible and intangible, the higher the quality of the LMX relationship. One critical element in this exchange of commodities is the perceived receptiveness of one party of the dyad to the other. In order for the exchange quality to develop there has to be a degree of perceived reciprocity and openness to ideas and requests of the other dyad member (Uhl-Bien \& Maslyn, 2003). Subordinates who believe their suggestions, ideas, and requests will go unheard will be less willing to offer them than those who believe they have the ear of the supervisor. Similarly, supervisors will be more likely to solicit input from subordinates they view as possessing ideas that are valuable to the discussion. Incorporating both supervisor and subordinate perspectives allows us to determine the extent to which dyad members perceive receptiveness in the relationships similarly, which should be related to agreement about LMX quality. Thus, we predict

H3: Deep-level perceived similarity within supervisor-subordinate dyads about receptiveness is positively related to supervisor-subordinate LMX agreement.

\section{Liking}

Liking, which is considered to be critical in the study of interpersonal interaction, is the third form of supervisor and subordinate deep-level perceptions we included. The foundation for the liking perception is based in role theory. Role theory (Kahn et al., 1964) suggests that supervisors and subordinates engage in social interactions during which work assignments are made by the supervisors. In general, more important organizational roles are given to subordinates whom the supervisors like, whereas lesser roles are given to those less liked. Subordinates selected for the more important roles establish close, high quality LMX relationships with their supervisors characterized by trust and emotional support (Graen \& Uhl-Bien, 1995). 
Liking has been shown to be strongly related to LMX in both laboratory and field settings (Liden et al., 1993; Wayne \& Ferris, 1990). The more a supervisor likes a subordinate, the more prone he or she is to offer the subordinate better opportunities. The subordinate will respond to this positive attention and developmental interest with increased liking for the supervisor, and exert more effort to do a good job, thereby engendering more liking on the part of the supervisor. This cyclical process will result in agreement about the high quality of the LMX relationship. Therefore, we predict

H4: Deep-level perceived similarity within supervisor-subordinate dyads about liking is positively related to supervisor-subordinate LMX agreement.

\section{Surface-level vs. Deep-level Similarity}

This study examines different forms of similarity between supervisors and subordinates as antecedents to LMX relationship quality agreement. Of these four predictors, one is an actual reflection of the dyad (surface-level) while the remaining three are perceptual in nature (deep-level). However, what is not clear is whether surface-level actual similarity or deep-level perceived similarity will be better predictors of LMX agreement. Although we believe that surface-level similarity is a starting point for consideration of LMX agreement, we contend that it plays a less significant role than deep-level perceived agreement. In other words, who you are on the surface matters much less with respect to LMX agreement than if you perceive you and your partner to be similar on deep issues. Deep-level perceived similarity regarding attitudes will have an impact on agreement about the quality of the supervisor-subordinate relationship above and beyond that exerted by surface-level demographic similarity.

H5: Deep-level perceived similarity (common perspective, receptiveness, and liking) explains additional variance beyond surface-level actual similarity in supervisorsubordinate LMX agreement.

\section{Method}

\section{Procedure}

We asked 65 managers employed by a government tax collection agency to participate in the study. Participation required each manager to complete a 2-page survey on the subordinates who reported directly to him or her. Supervisors were asked to write the name of a subordinate at the top of the form prior to completing it as a means of focusing their attention on the specific subordinate named. Upon receipt of the supervisors' surveys, we mailed each subordinate named on a supervisor survey a subordinate survey to complete. The subordinate survey was coded so that we could match it to the corresponding supervisor survey. The cover letter included with the subordinate survey indicated that the respondent's supervisor, who was named in the letter, had provided us his or her name as well as information about their relationship. The letter also indicated that participation was voluntary and that the supervisor would 
not see the responses offered by the subordinate.

\section{$\underline{\text { Respondents }}$}

\section{$\underline{\text { Supervisors }}$}

A total of $62(95 \%)$ managers composed the sample. The sex composition of the supervisor sample included $39(63 \%)$ males and $23(37 \%)$ females. The average age was 42 years. The managers had been employed by the agency an average of 11.3 years, in their current position an average of 3.4 years, and had an average of 9.5 years of supervisory experience. The positions held represented all levels of management from supervisor to top management. The racial distribution of the sample consisted of 39 (66\%) Caucasians, 12 (20\%) African-Americans, 6 (10\%) Hispanics, and 2 (3\%) Asians.

\section{Subordinates}

A total of $203(64 \%)$ usable subordinate surveys were returned to us. The gender breakdown for the sample included $102(50 \%)$ males and $95(47 \%)$ females. Six respondents left the gender question blank. Their average age was 46 years. The average tenure with the agency for the sample was 8.63 years, they had been in their current job an average of 3.49 years, and had been reporting to their current supervisor for an average of 2.76 years. The racial breakdown included $148(73 \%)$ Caucasians, 29 (14\%) African-Americans, 15 (7\%) Hispanics, 2 (1\%) Asians, and 9 (5\%) Other.

\section{Measures from Supervisors}

\section{Leader-Member Exchange}

We used the 7-item leader-member exchange (SLMX) scale from the leader's perspective to measure the manager's perceptions of the quality of the relationship he or she had with each subordinate (Liden et al., 1993). A sample item from this scale is "I think that I understand this subordinate's problems and needs." We adapted the response format so that respondents used a scale from 1 (strongly disagree) to 7 (strongly agree) rather than 1 to 5 to indicate their agreement with each question. The internal consistency estimate for this scale was .82 .

\section{Common Perspective With The Subordinate}

To measure the degree to which the supervisor perceived himself or herself to share a similar perspective with the subordinate, we used 6 items. Two items (i.e., "My subordinate and I see things in much the same way" and "My subordinate and I are similar in terms of our outlook, perspective, and values") were from Turban and Jones (1988), two items ("My subordinate and I think alike in terms of coming up with a similar solutions for a problem" and "My subordinate and I handle problems in a similar way") were from Liden et al. (1993), and we created the remaining two (i.e., "This subordinate 
and I hold similar attitudes concerning work-related issues" and "My subordinate and I have similar views on how his/her job should be performed") to round out our measure. Respondents indicated their agreement with the items on a 7-point (1=strongly disagree and $7=$ strong agree) Likert scale. The Cronbach alpha coefficient for this scale was .93. Given that the six items came from three different sources, we conducted an exploratory factor analysis to determine if they produced a unidimensional scale. The principal axis factoring analysis extracted only one factor with item loadings in the 80 s. These results coupled with the strong internal consistency estimate provide support for our use of these items as a unidimensional scale.

\section{$\underline{\text { Receptiveness To Subordinate }}$}

A total of five items were developed to tap the degree to which the supervisor was open and receptive to ideas and requests from the subordinate. Sample items from this scale include "I am usually receptive to any suggestions for change in our work group made by this subordinate" and "I usually fulfill requests made by this subordinate." Responses made on a 7-point Likert scale ( $1=$ strongly disagree and $7=$ strongly agree) produced a coefficient alpha of .80 .

\section{Liking For Subordinate}

We augmented the 2-item (i.e., "I like this subordinate very much as a person" and "I think this subordinate would make a good friend") Wayne and Ferris (1990) liking scale by adding a third item, "My subordinate is a very likable person." Responses to the items were made on a 7-point Likert scale with strong agreement at the high end of the scale. The items combined to produce an internal reliability estimate of .90 .

\section{Measures from Subordinates}

\section{Leader-Member Exchange}

The 7-item LMX scale from the member's perspective was used to measure the subordinates' perceptions of the quality of the relationship they had with their managers (Liden et al., 1993). A sample item from this scale is "I think that my supervisor understands my problems and needs." Respondents used a scale from 1 (strongly disagree) to 7 (strongly agree) to indicate their agreement with each question. The internal consistency estimate for this scale was .82 .

\section{Common Perspective With The Supervisor}

To measure the degree to which the subordinate perceived himself or herself to share a common perspective with the supervisor, we modified the 6 items we used to measure a common perspective with the subordinate. Specifically, we substituted the word supervisor for subordinate in each item (e.g., "My supervisor and I hold similar attitudes 
concerning work-related issues"). Responses made on a 7-point Likert scale (1=strongly disagree and $7=$ strongly agree). The Cronbach alpha coefficient for this scale was .93. Once again the results from the principal axis factoring analysis produced a one-factor solution with item loadings in the 80 s.

\section{Receptiveness Of Supervisor}

The five items used to measure receptiveness to the subordinate were modified to capture the degree of receptiveness felt by the subordinate. To accomplish this we rewrote the items from the subordinate's perspective (e.g., "My supervisor is usually receptive to any of my suggestions for change in our work group" and "If I ask for something from my supervisor or make a request, it is usually fulfilled in the way that I wanted." Responses made on a 7-point Likert scale ( $1=$ strongly disagree and $7=$ strongly agree) produced a coefficient alpha of .73.

\section{Liking For Supervisor}

We used three items that mirrored our measure of liking for the subordinate by substituting the word supervisor for subordinate (e.g., "My supervisor is a very likable person"). The subordinates used a 7-point Likert scale anchored with "strongly disagree" at 1 and "strongly agree" at 7 to respond. The internal consistency estimate for these items was .92 .

\section{Shared Variables}

To test the main premise of this paper, that deep-level perceived similarity is a stronger predictor of LMX agreement than surface-level actual similarity, as well as the individual hypotheses, we computed five variables: surface-level similarity and agreement scores for common perspective, receptiveness, liking, and LMX. Prior to creating these variables we estimated an 8-factor measurement model using LISREL 8.80 to establish the discriminant validity of our measures. The analyses included the items that compose the LMX, common perspective, receptiveness, and liking scales from both members of

the dyad. The model fit the data well $\left(X^{2}(751, \mathrm{~N}=203)=1107.93, p<.01, \mathrm{CFI}=.98, \mathrm{NFI}\right.$ $=.96, \mathrm{RMSEA}=.05)$ demonstrating that the measures we used to create our agreement variables were unique from one another. To further assess the discriminant validity of our scales, we followed a procedure outlined by Anderson and Gerbing (1988). Specifically, we set the correlation between two of our constructs to 1.00 and then performed a chi-square difference test between the constrained model and the measurement model. If the chi-square value for the measurement model is significantly lower than the chi-square when the correlation is set to 1.00 , discriminant validity between the scales is established. For our measurement model, this process required us to conduct 28 chi-square difference tests, all of which were significant. These results, which demonstrate that constraining the correlation between any pair of variables to 1.00 produces a worse fitting model than when the scales are allowed to naturally correlate, offer evidence of discriminant validity. 
Surface-level similarity was created by developing discrepancy scores by subtracting the subordinate's value of age, race, and sex from the supervisor's. These scores were then divided by their respective standard deviations, summed, and then reverse scored so that high values reflect high similarity (Liden et al., 1993; Turban \& Jones, 1988). Scores on our relational demography variable ranged from 0 to 6.80 .

To calculate the agreement scores for the perceptual similarity variables, we followed the steps outlined by Schriesheim et al. (2001) for the individuals within- and betweendyads analysis. The underlying assumption of this approach is that "neither the supervisor nor the subordinate compares his/her dyadic relationship to any other relationship within the work group" (p. 531). When this is the case, the between unit of analysis is the supervisor-subordinate dyad and the within unit of analysis is the "description of each dyad by the supervisor and by the subordinate" ( $p$ 531). The between scores are calculated by averaging the responses on the scales of interest for both the supervisor and the subordinate. The within scores are computed by subtracting the between score for either party from the other's corresponding score. In our case, the subordinate's value was subtracted from the supervisor's. This approach resulted in agreement scores for common perspective ranging from -3.83 to 3.67 , for receptiveness ranging from -2.57 to 4.43 , for liking ranging from -3.00 to 4.40 , and for LMX ranging from -4.00 to 3.67 . In all cases, negative scores indicate that the supervisor's value was lower than the subordinate's.

\section{Control Variables}

As past research has shown (Maslyn \& Uhl-Bien, 2001; Wayne, Shore, \& Liden, 1997; Wayne, Liden, Kraimer, \& Graf, 1999), one influence on LMX quality is the human capital members bring to the relationship. To account for this, we employed five human capital control variables. The first set of control variables were three forms of tenure: job tenure, organizational tenure, and tenure with the supervisor, all measured in months. Past research has demonstrated a significant relationship between LMX and each of these forms of tenure (Duarte, Goodson, \& Klich, 1994; Wayne et al., 1997; Wayne et al., 1999). The two other human capital variables were education and hours worked per week. Education was measured by asking the respondents to indicate the highest degree they had completed ranging from GED to PhD/MD, while hours worked per week was a self-reported average. Again, research has shown both of these variables to be related to LMX quality (Wayne et al., 1999).

\section{Data Analyses}

We used hierarchical linear modeling (HLM; Raudenbush, Bryk, Cheong, \& Congdon, 2004 ) to test our three hypotheses. Even though our data are dyadic, each supervisor rated multiple subordinates. Thus, there is the potential that the ratings are not independent. For instance, supervisors may have used their "best" subordinate as the top anchor rather than "7" which was the top score possible which would artificially restrict the range within supervisors. It is also possible that the supervisors fell victim to common rating errors such as leniency or strictness which also would have limited the 
variance in the ratings made by a particular supervisor. HLM allows for the modeling of supervisor effects while testing the study hypotheses. Our HLM analyses were composed of multiple steps using grand mean centered variables. On the first step we entered the control variables. On the second step we entered just the surface-level similarity measure of relational demography. On the third step we entered just the deeplevel similarity measures of common perspective, receptiveness, and liking. On the final step we entered both the surface-level and deep-level similarity antecedents.

We are aware that Edwards $(1994,1995)$ has developed statistical analyses (e.g., response surface methodology) that are useful when examining agreement (i.e., difference) scores. However, similar to Sacco, Scheu, Ryan, and Schmitt (2003), this approach is not a viable analytic technique for our study. Edwards has presented techniques that are appropriate when the independent variables are expressed as difference scores or when the dependent variable is measured as a difference score but not both. After rigorous research, testing, and communications with multiple scholars knowledgeable with this technique, we determined that we were unable to use this technique to analyze our data because both our independent and dependent variables are difference scores. In addition, we could have used ordinary least squares (OLS) regression to perform our analyses as the results for OLS regression were very similar to those we report for HLM. However, we believe that using HLM provides a more stringent test and allows us to take into consideration the nested structure of our data.

\section{Results}

Means, standard deviations, and correlations among the variables of interest are provided in Table 1. While not used in our analyses, we also included both supervisor and subordinate LMX ratings in Table 1. The correlation between these two scales (.34) is similar to that found in previous studies (Gerstner \& Day, 1997 ). Prior to testing our first hypotheses, we ran a null model equation to determine the degree of nonindependence in our dependent variable, LMX agreement. This test, which is equivalent to a one-way analysis of variance (ANOVA) of supervisory effects on LMX ratings, was significant $\left(X^{2}(62, N=203)=143.03, p<.001\right)$ indicating systematic betweensupervisor variance in LMX ratings. The intraclass correlation coefficients (Hofmann, Griffin, \& Gavin, 2000) showed that the percentage of variance in ratings residing between supervisors was .49, supporting our decision to use HLM to model this variance. 
Table 1

Means, Standard Deviations, and Correlations ${ }^{a}$

\begin{tabular}{|c|c|c|c|c|c|c|c|c|c|c|c|c|c|}
\hline Variable & Mean & SD & 1 & 2 & 3 & 4 & 5 & 6 & 7 & 8 & 9 & 10 & 11 \\
\hline $\begin{array}{l}\text { 1. Relational } \\
\text { demography }\end{array}$ & 4.90 & 1.53 & & & & & & & & & & & \\
\hline 2. LMX agreement & 0.35 & 1.29 & -.13 & & & & & & & & & & \\
\hline $\begin{array}{l}\text { 3. Common perspective } \\
\text { agreement }\end{array}$ & -0.09 & 1.39 & -.12 & $64^{*+*}$ & & & & & & & & & \\
\hline $\begin{array}{l}\text { 4. Receptiveness } \\
\text { agreement }\end{array}$ & 0.58 & 1.20 & -.03 & $.58^{*+*+}$ & $.68^{*+*}$ & & & & & & & & \\
\hline 5. Liking agreement & -0.17 & 1.39 & .04 & $.51^{* * *}$ & $.55^{* * *}$ & $.43^{* * * *}$ & & & & & & & \\
\hline 6. Organizational tenure & 8.63 & 7.55 & $.17^{*}$ & -.10 & -.11 & -.12 & .08 & & & & & & \\
\hline 7. Supervisor tenure & 2.76 & 1.88 & .07 & -.01 & .04 & -.06 & .13 & $.35^{* *+}$ & & & & & \\
\hline 8. Job tenure & 3.49 & 2.97 & .09 & .04 & -.02 & -.04 & -.01 & $.45^{* * *}$ & $.40^{*+*+}$ & & & & \\
\hline 9. Education & 2.13 & 0.99 & -.03 & .09 & $.15^{*}$ & .11 & .04 & $-.28^{\text {***t }}$ & -.08 & -.05 & & & \\
\hline $\begin{array}{l}\text { 10. Hours worked per } \\
\text { week }\end{array}$ & 42.27 & 5.80 & $.20^{* *}$ & .03 & .04 & .08 & .06 & .14 & -.03 & $.19^{*}$ & .10 & & \\
\hline 11. Supervisor LMX & 5.56 & 0.74 & -.02 & $.22^{* *}$ & $.28^{* * t}$ & $.24^{* *}$ & $.18^{*}$ & -.09 & $-.18^{*}$ & -.11 & .07 & .02 & \\
\hline 12. Subordinate LMX & 5.21 & 1.34 & .12 & $-.84^{* * * x}$ & $-.47^{* * x}$ & $-.43^{4 * * x}$ & $-.40^{* * *}$ & .05 & -.09 & -.10 & -.05 & -.02 & $.34^{n+x}$ \\
\hline
\end{tabular}

Note: $\mathrm{LMX}=$ Leader-Member Exchange.

${ }^{a} \mathrm{n}=203$.

${ }^{*} p<.05 .{ }^{* *} p<.01 .{ }^{* * *} p<.001$.

The HLM results for our hypotheses are shown in Table 2. Model 1 shows the results for our control variables. Only organizational tenure was a significant predictor of LMX agreement. The variance explained in LMX agreement by this step was less than $1 \%$. Model 2 shows that organizational tenure remained significant and the main effect for surface-level similarity, measured by relationship demography, on LMX agreement ratings also was significant. This finding provides support for Hypothesis 1 . The variance explained in LMX agreement by this step was $1 \%$.

Model 3 shows the results for the three deep-level agreement variables, common perspective agreement, receptiveness agreement, and liking agreement. In this step, organizational tenure is no longer significant, but job tenure is. All three deep-level perceptual agreement variables were significant and this step explained $46 \%$ of the variance in LMX agreement. These results offer support for Hypotheses 2 through 4.

Model 4, which includes both the surface-level actual agreement variable and the deeplevel perceived agreement variables, tests Hypothesis 5. Once again, in this step our control variable of job tenure was significant. Results indicate that the actual surfacelevel agreement variable was not significant but the three deep-level perceived 
variables were. Our findings offer support for Hypothesis 5 as no additional variance in LMX agreement was

Table 2

Hierarchical Linear Modeling Results for LMX Agreement ${ }^{a}$

\begin{tabular}{|c|c|c|c|c|}
\hline Variables & Model 1 & $\begin{array}{r}\text { Model } \\
2 \\
\end{array}$ & $\begin{array}{r}\text { Model } \\
3 \\
\end{array}$ & $\begin{array}{r}\text { Model } \\
4\end{array}$ \\
\hline Controls & $\mathrm{Y}$ & $\mathrm{Y}$ & $\mathrm{Y}$ & $\mathrm{Y}$ \\
\hline Organizational tenure & $-.002^{*}$ & $-.002^{*}$ & -.001 & -.001 \\
\hline Supervisor tenure & .001 & .001 & -.003 & -.003 \\
\hline Job tenure & .003 & .003 & $.004^{*}$ & $.004^{*}$ \\
\hline Hours worked & .007 & .012 & -.005 & -.001 \\
\hline Education & .074 & .077 & -.019 & -.019 \\
\hline Main effects & & & & \\
\hline Relational demography & & $-.112^{*}$ & & -.075 \\
\hline Common perspective agreement & & & $.334^{\star * *}$ & $.316^{* * *}$ \\
\hline Receptiveness agreement & & & $.243^{* *}$ & $.250^{\star *}$ \\
\hline Liking agreement & & & $.220^{\star *}$ & $.229^{\star \star}$ \\
\hline$\Delta R^{2}$ & .00 & $.01^{*}$ & $.46^{* *}$ & $.46^{\star *}$ \\
\hline
\end{tabular}

explained when the actual surface-level agreement variable was added to the equation that housed the three deep-level perceived similarity agreement variables.

\section{Discussion}

Examining LMX as a dyadic exchange has been identified as an important yet overlooked component in the study of LMX (Schriesheim et al., 1999; 2001). To help fill this void, we examined actual surface-level and deep-level perceived similarity between dyadic members as predictors of LMX agreement. We did find support for Hypothesis 1, that surface-level similarity (i.e., relational demography) was significantly related to LMX agreement, but only when it was the only predictor in the equation. This result is similar to those reported by other studies of relational demography on both member and leader-rated LMX (Green et al., 1996; Liden et al., 1993). However, once we entered our deep-level perceived similarity variables, surface-level actual similarity became insignificant, but all of the deep-level similarity variables calculated as agreement scores were significantly related to LMX agreement. Results from this study therefore illustrate that agreement between supervisors and subordinates on deep-level perceived similarity is a better predictor of LMX agreement than is surface-level similarity. 


\section{Strengths and Limitations of the Present Study}

This study possesses a number of strengths. First, this study extends research on LMX and provides a unique contribution to the literature by examining LMX agreement, as has been called for by LMX researchers (Gerstner \& Day, 1997; Scandura, 1999; Schriesheim et al., 1999; 2001). Second, in this study we not only examined agreement between supervisors and subordinates about their relationship quality, but we also examined surface-level and deep-level similarity from both members of the dyad. This approach allowed us to examine agreement between leaders and members about their similarity. In so doing, we were able to examine our variables on the same level of analysis (Dansereau \& Yammarino, 2006), and in the process eliminate some of the problems of common method variance as the components of our independent and dependent variables came from different sources (Podsakoff, MacKenzie, Lee, \& Podsakoff, 2003). Third, we found significant results even after controlling for job tenure, organizational tenure, supervisor tenure, education, and number of hours worked per week, all of which have been identified as theoretically important variables.

Although there are a number of strengths in this study, there are limitations that need to be acknowledged to properly interpret the study's results. A first limitation is that the dominant race for both supervisors and subordinates in the sample was Caucasian. This high percentage of Caucasians may have influenced the relational demography variable and may limit the generalizability of the results. A second limitation was that our measures for deep-level perceptual similarity have not been used in previous studies. The seriousness of this limitation is somewhat mitigated by the fact that many of the items used to create these scales came from published studies, the items produced acceptable internal consistency estimates, and the measurement model for the data fit well. A third limitation was that our cross-sectional data do not allow us to comment on the development of LMX relationships. As a result, future research efforts should examine LMX agreement over time. A final limitation is that only a subset of the subordinates who reported to a supervisor was included and supervisors were allowed to select the subordinates they rated. Although there was acceptable variance on LMX quality as rated by the supervisors, using random selection of subordinates would have reduced any potential sampling bias.

\section{Practical Implications}

The findings in this study have important implications for practitioners. If supervisors can be made aware of the predictors of LMX agreement, they will be better positioned to capitalize on these antecedents in their relationships with their subordinates and maximize their associated outcomes. In particular, if there are problems with the quality of LMX relationships, managers could make attempts to staff leaders with subordinates who share common perspectives, are receptive to one another, and enjoy working together. However, managers also need to realize that leaders and subordinates who share deep-level similarity and agree on their LMX levels may not always be optimal for the organization. For example, although leaders and members who share common 
perspectives are likely to have higher levels of LMX agreement, such a situation could also have the potential to contribute to a stagnation of ideas, promotion of norms, and "status quo" thinking. Additionally, managers need to be cognizant that leaders do not provide undeserving advantages and benefits to those subordinates with whom they share common perspectives, are more receptive, or like more on a personal level. This can be accomplished by having objective performance criteria that fairly reward strong performers on the job, regardless of the level of deep-level similarity or LMX agreement.

On a different note, this study also offers implications for subordinates who find themselves working for a supervisor with whom they do not perceive deep-level similarity. When employees have some degree of choice over who their supervisor will be (such as when interviewing), every effort should be made to avoid a relationship where there are striking differences in approach and attitudes towards work. Subordinates who find themselves unable to avoid such situations should recognize the limitations a lack of perceived deep-level similarity introduces into their relationship. If these limitations are unacceptable, then efforts to move to a different work group may be their best course of action.

\section{Directions for Future Research}

Our study, which specifically focused on antecedents of LMX agreement, is a much needed step in LMX research. However, this paper is only a first step; there is much more to learn. Examining other antecedents of LMX agreement will be important in the future. In particular, we think future research should investigate communication frequency, feedback seeking/receiving, and personality similarity (Huang \& lun, 2006) as each are key components in building LMX quality. Further, future research should attempt to examine both the antecedents and outcomes from LMX agreement, as a single study that investigates both predictors and consequences would be a valuable addition to the LMX literature.

There are a number of other important questions that can be answered with the use of LMX agreement scores. For instance, what happens when supervisor and subordinate LMX ratings do not agree? Is ignorance bliss? Will better outcomes for subordinates result when they believe the relationship quality is high even though the supervisor thinks the quality is low, than when both agree that the relationship quality is low? Or, do subordinates, starved for the attention they believe they deserve from their supervisors, become disillusioned and poison the work environment? Further exploring LMX agreement scores will help shed light on these and other interesting relationship questions.

In conclusion, this study offers some new insights regarding LMX relationships (Liden et al., 1997). By examining LMX agreement from various theoretical perspectives and considering both surface-level and deep-level antecedents, we were able to take an initial step in filling a gap in the extant LMX literature. Our findings suggest regardless of the surface-level similarity that may exist between supervisors and their subordinates, deep-level perceptual similarity is a far better predictor of LMX relationship quality 
agreement.

\section{References}

Allison, C. W., Armstrong, S. J., \& Hayes, J. (2001). The effects of cognitive style on leader-member exchange: A study of manager-subordinate dyads. Journal of Occupational and Organizational Psychology, 74, 201-220.

Anderson, J. C. \& Gerbing, B. W. (1988). Structural equation modeling in practice: A review and recommended twp-step approach. Psychological Bulletin, 103, 411423.

Bauer, T. N., \& Green, S. G. (1996). The development of leader-member exchange: A longitudinal test. Academy of Management Journal, 39, 1538-1567.

Blau, P. M. (1964). Exchange and power in social life. New York: Wiley.

Byrne, D. (1971). The attraction paradigm. New York: Academic Press.

Chatman, J., Polzer, J., Barsade, S., \& Neale, M. (1998). Being different yet feeling similar: The influence of demographic composition and organizational culture on work processes and outcomes. Administrative Science Quarterly, 43, 749-780.

Cogliser, C. C., Schriesheim, C. A., Scandura, T. A., \& Gardner, W. L. (in press). Balance in leader and follower perceptions of leader-member exchange: Relationships with performance and work attitudes. Leadership Quarterly.

Cropanzano, R., \& Mitchell, M. S. (2005). Social exchange theory: An interdisciplinary review. Journal of Management, 31, 874-900.

Dansereau, F., Cashman, \& Graen, G. B. (1973). Instrumentality theory and equity theory as complementary approaches in predicting the relationship of leadership and turnover among managers. Organizational Behavior and Human Performance, 10, 184-200.

Dansereau, F., \& Yammarino, F. J. (2006). Is more discussion about levels of analysis really necessary? When is such discussion sufficient? Leadership Quarterly, 17, $537-552$.

Duarte, N. T., Goodson, J. R., \& Klich, N. R. (1994). Effects of dyadic quality and duration on performance appraisal. Academy of Management Journal, 37, 499521.

Edwards, J. R. (1994). The study of congruence in organizational behavior research: Critique and a proposed alternative. Organizational Behavior and Human Decision Processes, 58, 51-100 (erratum 58, 323-325). 
Edwards, J. R. (1995). Alternatives to difference scores as dependent variables in the study of congruence in organizational research. Organizational Behavior and Human Decision Processes, 64, 307-324.

Engle, E. M., \& Lord, R. G. (1997). Implicit theories, self-schemas, and leader-member exchange. Academy of Management Journal, 40, 988-1010.

Gerstner, C. R., \& Day, D. V. (1997). Meta-analytic review of leader-member exchange theory: Correlates and construct issues. Journal of Applied Psychology, 82, 827844.

Gouldner, A. W. (1960). The norm of reciprocity: A preliminary statement. American Sociological Review, 25, 161-177.

Graen, G. B., \& Uhl-Bien, M. (1995). Development of leader-member exchange (LMX) theory of leadership over 25 years: Applying a multi-level multi-domain perspective. Leadership Quarterly, 6, 219-247.

Green, S. G., Anderson, S. E., \& Shivers, S. L. (1996). Demographic and organizational influences on leader-member exchange and related work attitudes. Organizational Behavior and Human Decision Processes, 66, 203-214.

Gregurus, G. \& Ford, J. M. (2006). An examination of the multidimensionality of supervisor and subordinate perceptions of leader-member exchange. Journal of Occupational and Organizational Psychology, 79, 433-465.

Harrison, D. A., Price, K. H., \& Bell, M. P. (1998). Beyond relational demography: Time and the effects of surface- and deep-level diversity on work group cohesion. Academy of Management Journal, 41, 96-107.

Hofmann, D. A., Griffin, M. A. \& Gavin, M. B. (2000). The application of hierarchical linear modeling to organizational research. In K. J. Klein \& S. W. J. Kozlowski (Eds.), Multilevel theory, research, and methods in organizations: Foundations, extensions, and new directions. (SIOP Frontiers Series). San Francisco, CA: Jossey-Bass.

Huang, X., \& lun, J. (2006). The impact of subordinate-supervisor similarity in growthneed strength on work outcomes: The mediating role of perceived similarity. Journal of Organizational Behavior, 27, 1121-1148.

Jackson, S. E., Stone, V. K., \& Alvarez, E. B. (1993). Socialization amidst diversity: Impact of demographics on work team oldtimers and newcomers. In L.L. Cummings \& B.M. Staw (Eds.), Research in Organizational Behavior (Vol. 15: 45-109). Greenwich, CT: JAI Press. 
Kahn, R. L., Wolfe, D. M., Quinn, R. P., Snoek, J. D., \& Rosenthal, R. A. (1964). Organizational stress: Studies in role conflict and ambiguity. New York: Wiley.

Lewin, K. (1947). Frontiers in group dynamics: concept, method and reality in social science; social equilibria and social change. Human Relations, 1, 5-41.

Liden, R. C., \& Graen, G. (1980). Generalizability of the vertical dyad linkage model of leadership. Academy of Management Journal, 23, 451-465.

Liden, R. C., Sparrowe, R. T., \& Wayne, S. J. (1997). Leader-member exchange theory: The past and potential for the future. In. G. R. Ferris (Ed.), Research in Personnel and Human Resource Management (Vol. 15, pp. 47-120). Greenwich, CT: JAI Press.

Liden, R. C., Wayne, S. J., \& Stilwell, D. (1993). A longitudinal study on the early development of leader member exchanges. Journal of Applied Psychology, 78, 662-674.

McClane, W. E. (1991). The interaction of leader and member characteristics in the leader-member exchange (LMX) model of leadership. Small Group Research, 22: 283-300.

Maslyn, J. M., \& Uhl-Bien, M. (2001). Leader-member exchange and its dimensions: Effects of self-effort and other's effort on relationship quality. Journal of Applied Psychology, 86, 697-708.

Pelled, L. H., \& Xin, K. R. (2000). Relational demography and relationship quality in two cultures. Organization Studies, 21, 1077-1094.

Phillips, A. S. \& Bedeian, A. G. (1994). Leader-follower exchange quality: The role of personal and interpersonal attributes. Academy of Management Journal, 37, 9901001.

Phillips, K. W., Northcraft, G. B., \& Neale, M. A. (2006). Surface-level diversity and decision-making in groups: When does deep-level similarity help? Group Processes \& Intergroup Relations, 9, 467-482.

Podsakoff, P. M., MacKenzie, S. B., Lee, J., \& Podsakoff, N. P. (2003). Common method biases in behavioral research: A critical review of the literature and recommended remedies. Journal of Applied Psychology, 88, 879-903.

Raudenbush, S., Bryk, A., Cheong, Y. F., \& Congdon, R. (2004). HLM6: Hierarchical linear and nonlinear modeling. Lincolnwood, IL: Scientific Software International, Inc.

Sacco, J. M., Scheu, C. R., Ryan, A. M., \& Schmitt, N. (2003). An investigation of race 
and sex similarity effects in interviews: A multilevel approach to relationship demography. Journal of Applied Psychology, 88, 852-865.

Scandura, T. A. (1999). Rethinking leader-member exchange: An organizational justice perspective. Leadership Quarterly, 10, 25-40.

Schriesheim, C. A., Castro, S. L., \& Cogliser, C. C. (1999). Leader-member exchange (LMX) research: A comprehensive review of theory, measurement, and dataanalytic practices. Leadership Quarterly, 10, 63-113.

Schriesheim, C. A., Castro, S. L., Zhou, X. T., \& Yammarino, F. J. (2001). The folly of theorizing " $A$ " while testing "B" A selective level-of-analysis review of the field and a detailed Leader-Member-Exchange illustration. Leadership Quarterly, 12, 515551.

Tsui, A. S., \& O'Reilly, C. A. (1989). Beyond simple demographic effects: The importance of relational demography in superior-subordinate dyads. Academy of Management Journal, 32, 402-423.

Turban, T. D., Dougherty, T., \& Lee, F. K. (2002). Gender, race, and perceived similarity effects in development relationships: The moderating role of relationship duration. Journal of Vocational Behavior, 61, 240-262.

Turban, D. B., \& Jones, A. P. (1988). Supervisor-subordinate similarity: Types, effects, and mechanisms. Journal of Applied Psychology, 73, 228-234.

Tyran, K. L., \& Gibson, C. B. (2008). Is what you see, what you get?: The relationship among surface- and deep-level heterogeneity characteristics, group efficacy, and team reputation. Group \& Organization Management, 33, 46-76.

Uhl-Bien, M., \& Maslyn, J. M. (2003). Reciprocity in manager-subordinate relationships: Components, configurations, and outcomes. Journal of Management, 29, 511532.

Vecchio, R. P., \& Brazil, D. M. (2007). Leadership and sex-similarity: A comparison in a military setting. Personnel Psychology, 60, 303-335.

Wang, H., Law, K. S., Hackett, R. D., Wang, D., \& Chen, Z. X. (2005). Leader-member exchange as a mediator of the relationship between transformational leadership and followers' performance and organizational citizenship behavior. Academy of Management Journal, 48, 420-432.

Wayne, S. J. \& Ferris, G. R. (1990). Influence tactics, affect, and exchange quality in supervisor-subordinate interactions: A laboratory experiment and field study. Journal of Applied Psychology, 75, 487-499. 
Wayne, S. J., \& Liden, R. C. (1995). A longitudinal study of the effects of impression management on performance ratings. Academy of Management Journal, 38, 232-260.

Wayne, S. J., Liden, R. C., Kraimer, M. L., \& Graf, I. K. (1999). The role of human capital, motivation and supervisor sponsorship in predicting career success. Journal of Organizational Behavior, 20, 577-595.

Wayne, S. J., Shore, L. M., \& Liden, R. C. (1997). Perceived organizational support and leader-member exchange: A social exchange perspective. Academy of Management Journal, 40, 82-111.

Yammarino, F. J., \& Dubinsky, A. J. (1992). Superior-subordinate relationships: A multiple levels of analysis approach. Human Relations, 45, 575-600. 